\title{
Effects of passion fruit peel flour as a dietary fibre resource on biscuit quality
}

\author{
Minjie WENG ${ }^{1}$ (D), Yibin $\mathrm{LI}^{1}$, Li WU ${ }^{1}$, Hengguang ZHENG ${ }^{1}$, Pufu LAI ${ }^{1}$, Baosha TANG ${ }^{1}$, Xuhui LUO ${ }^{2,3^{*}}$
}

\begin{abstract}
The purpose of this investigation was to evaluate the effects of the addition of passion fruit peel flour (PFPF) from two different species to biscuits. Each PFPF was added to biscuit flour in different amounts (wheat flour replacement rate: $0 \%, 5 \%, 10 \%$, and $15 \%$ ). The colour and textural properties of the doughs and biscuits were evaluated. The physical characteristics, sensory characteristics and dietary fibre content of the biscuits were tested. Both types of PFPF show a higher fat absorption capacity $(2.44 \mathrm{~g} / \mathrm{g}$ (yellow) and $2.38 \mathrm{~g} / \mathrm{g}$ (purple)). The results showed that the PFPF could significantly improve the texture of the prepared biscuits but showed an adverse effect on the colour. This study has shown that incorporation of PFPF (5\%) can produce fibre-rich (TDF, 2.05\% and 2.08\%) biscuits with low water content (2.20\% and 2.28\%), excellent texture characteristics (Firmness, $13.18 \mathrm{~N}$ and $15.68 \mathrm{~N}$ ) and good sensory quality.
\end{abstract}

Keywords: passion fruit peel flour; dietary fibre biscuits; colour; texture; sensory.

Practical Application: The results of this study showed that the application of PFPF in biscuit production has great development potential. The research on various characteristics of PFPF also provides reference for the development in other foods.

\section{Introduction}

Biscuits are popular bake food product that are widely loved by children, adults and the elderly (Okpala \& Okoli, 2013). Biscuits have the advantages of a relatively long shelf life, affordable cost, high nutritional value, a ready-to-eat nature and a sweet taste (Garcia-Armenta et al., 2017). However, along with the prevalence of functional foods and nutraceuticals, new requirements are placed on different types of ready-to-eat foods (including biscuits) requiring that foods that both nutritious and healthy (Aparicio-Saguilán et al., 2007), such as gluten free biscuit basing on foxtail (Singh \& Kumar, 2018) and eco-friendly biscuit using by-product of potato industry (Morais et al., 2018).

Passion fruit is widely grown in South America, Asia, Oceania and Africa and comprises approximately 450-500 species (Dhawan et al., 2004; Ferreres et al., 2007). The flesh of passion fruit can be directly eaten, blended into a drink, or made into salads, jellies, ice cream and fruit-flavoured candies (Liew et al., 2014). In the production process of passion fruit juice, a large amount of peel waste is produced, and the quantity of these peels accounts for more than half of the total mass of the fruit (Silva et al., 2014). The main component of the peel is the pith, containing a large amount of fibre and pectin, which can be used in the production of functional foods (Coelho et al., 2017). According to some studies, the content of dietary fibre in passion fruit peel ranges from 57.9 to $81.9 \mathrm{~g} / 100 \mathrm{~g}$ dry mass (Hernández-Santos et al., 2015; MacAgnan et al., 2015; Yapo \& Koffi, 2008). The pectin content ranges from 12.6 to $18.2 \mathrm{~g} / 100 \mathrm{~g}$ dry mass (Freitas de Oliveira et al., 2016; Kliemann et al., 2009; Seixas et al., 2014). The antioxidant content (ascorbic acid ( $41.98 \mathrm{mg} / 100 \mathrm{~g}$ dry mass), polyphenols (482.56 mg GAE/100 g dry mass) and carotenoids
(4.85 $\mathrm{mg} \beta$-carotene/100 g dry mass)) was higher in peel than in the flesh (Hernández-Santos et al., 2015).

Flours made of fruits are potential sources of some fibres and represent valuable economical alternatives of processed foods (Santos et al., 2017). The peel of passion fruit can be made into a product called passion fruit peel flour (PFPF) through a drying and milling process. It has been found that PFPF has a certain blood sugar lowering function and is used in Brazil for adjuvant treatment of diabetes (Smith et al., 2012). The addition of different classes of ingredients (fibres, peels, pomace, seeds, etc.) in the formulation of biscuits and other foods may improve their quality. Oat and wheat fibres decreased the moisture content and water activity of Chhana-murki (Gurditta et al., 2019). Fruit (grape, apricot, apple) and grain (rice, corn, sunflower, barley) based by-products rich in dietary fibres could improve survival of probiotic strains ice scream without any adverse effects (Ayar et al., 2018). Fortified biscuits with citrus peel powders reduced the levels of serum cholesterol, i.e., triglycerides and low density lipoprotein cholesterol, both of which are known to contribute to disorders such as diabetes, obesity and an increased risk of heart disease (Youssef et al., 2014). Adding mango peel powder to soft dough biscuits can significantly increase their fibre content and oxidation resistance (Ajila et al., 2008). Short dough biscuits fortified with apple pomace were found to reduce the glycaemic index of the biscuits (Alongi et al., 2019). The addition of flaxseed contributed to the variety of phenolic acids and improved the lignan concentration in biscuits (Čukelj et al., 2017). However, investigations on the application of passion fruit peel as a supplementation in biscuit formulas is still limited.

${ }^{1}$ Institute of Agricultural Engineering Technology, Fujian Academy of Agricultural Sciences, Fuzhou, Fujian Province, China

${ }^{2}$ Agricultural Ecology Institute, Fujian Academy of Agricultural Sciences, Fuzhou, Fujian province, China

${ }^{3}$ Fujian Key Laboratory of Agricultural Ecological Process in Red Soil Hilly Region, Fujian Academy of Agricultural Sciences, Fuzhou, Fujian province, China

${ }^{*}$ Corresponding author: xuhui22203@163.com 
Therefore, the purpose of this investigation was to evaluate the effect of the addition of two species (Passiflora edulis Sims. (purple passion fruit) and Passiflora edulis f. flavicarpa (yellow passion fruit)) of passion fruit peel flour to biscuits. The effect of different concentrations of PFPF on the dough characteristics was also studied.

\section{Materials and methods}

\subsection{Sample preparation and storage conditions}

Wheat flour (WF) was purchased from a local supermarket. Two types of passion fruit were purchased from Fuzhou Lu Jiang Nan Agriculture Development Co., Ltd. The fruits were cleaned in distilled water. The cleaned fruits were cut in half, and the pulp and seeds were completely removed. The peels were washed in distilled water and dried at $60^{\circ} \mathrm{C}$ in a hot air dryer for $48 \mathrm{~h}$. The dry peels were milled in a grinder. The PFPFs were obtained and had a particle size of $600-800 \mu \mathrm{m}$. The PFPFs were used as additives in biscuit preparation.

\subsection{Fibre analysis of PFPF}

The dietary fibre content of the samples, such as the soluble dietary fibre (SDF), insoluble dietary fibre (IDF) and total dietary fibre (TDF), were determined by the gravimetric enzymatic method (Yapo \& Koffi, 2008).

\subsection{Physical characterization of PFPF}

\section{Bulk Density (BD)}

A PFPF sample was gently loaded into a $10 \mathrm{~mL}$ tar-coated cylinder. The bottom of the cylinder was gently tapped against the table until the sample level no longer changed. The sample weight per unit volume was recorded as bulk density $(\mathrm{g} / \mathrm{mL})$ (Kaur \& Singh, 2005).

\section{Colour Measurement}

The colour measurement of the PFPF sample was carried out by utilizing a colorimeter (CM-3500d, Konica Minolta, Japan). The reference was Illuminant D65, and the visual angle was $10^{\circ}$. The experimental results were acquired by the CIELab system (Krystyjan et al., 2015).

\section{Swelling Capacity (SC)}

A PFPF sample (200 mg) was loaded in a calibrated cylinder $(1.0 \mathrm{~cm}$ diameter), and then $10 \mathrm{~mL}$ of distilled water containing $0.02 \%$ azide was added. The sample was incubated for $18 \mathrm{~h}$ at $25^{\circ} \mathrm{C}$. The bed volume was measured and represented as volume/g original PFPF weight (Kuniak C. Sc. \& Marchessault, 1972).

\section{Water Solubility Index (WSI)}

A sample $(2.000 \mathrm{~g})$ was mixed well with $50 \mathrm{~mL}$ of distilled water and was incubated in a water bath at $90{ }^{\circ} \mathrm{C}$ for $15 \mathrm{~min}$. The sample was cooled at $25^{\circ} \mathrm{C}$ for $20 \mathrm{~min}$ and centrifuged at $5000 \mathrm{rpm}$ for $10 \mathrm{~min}$. The supernatant was slowly poured into a tar-coated evaporating dish. The supernatant was evaporated at $110^{\circ} \mathrm{C}$ for $12 \mathrm{~h}$, and the weight of the dry matter was weighed. The WSI (Ben Jeddou et al., 2017) was calculated using the following formula: WSI $(\%)=$ (weight of dissolved solids in supernatant/weight of dry solids) $\times 100$.

\section{Water-Holding Capacity (WHC)}

A PFPF sample $\left(2.000 \mathrm{~g}, \mathrm{~m}_{0}\right)$ was loaded in a centrifuge tube, and then the tube with the PFPF sample was weighed $\left(\mathrm{m}_{1}\right)$. Then, $30 \mathrm{~mL}$ of distilled water was added with a pipette and incubated for $18 \mathrm{~h}$ at $25^{\circ} \mathrm{C}$. The PFPF suspension was centrifuged at $8000 \mathrm{rpm}$ for $15 \mathrm{~min}$. The supernatant was poured out. The centrifuge tube was inverted on a test tube rack with absorbent paper underneath, allowed to stand until the water completely drained, and then weighed $\left(\mathrm{m}_{2}\right)$. The WHC was calculated by the following equation: WHC ( $\mathrm{g}$ water/g PFPF $)=\left(\mathrm{m}_{2}-\mathrm{m}_{1}\right) / \mathrm{m}_{0}$ (Robertson et al., 2000).

\section{Fat-Binding Capacity (FAC)}

A PFPF sample $\left(2.000 \mathrm{~g}, \mathrm{~m}_{0}\right)$ was loaded into a centrifuge tube, and then the tube with the PFPF sample was weighed $\left(m_{1}\right)$. Ten millilitres of soybean oil was added with a pipette. The mixture was vortexed for $30 \mathrm{~min}$ and then centrifuged at $8000 \mathrm{rpm}$ for $15 \mathrm{~min}$. The oil layer was poured out, and the centrifuge tube was inverted on a test tube rack with absorbent paper underneath, allowed to stand until the water completely drained, and then weighed $\left(\mathrm{m}_{2}\right)$. The FAC (Ben Jeddou et al., 2017) was calculated by the following Equation 1:

FAC $(\mathrm{g}$ oil $/ \mathrm{g}$ PFPF $)=\left(m_{2}-m_{1}\right) / m_{0}$

\subsection{Dough properties analysis}

Doughs were made from mixtures including wheat flour substitutions of 5\%, 10\% and 15\% PFPF. Dough made without PFPF was denoted as the control. Therefore, the yellow passion fruit test group was labelled as W950Y050, W900Y100, and W850Y150, and the purple passion fruit test group was labelled as W950P050, W900P100, and W850P150. The doughs were made with the following formula: dough sample $=100 \mathrm{~g}$ (wheat flour or PFPF mixtures) $+60 \mathrm{~mL}$ distilled water $+0.25 \mathrm{~g} \mathrm{NaCl}$.

\section{Colour analysis}

Each test sample underwent colour measurement before being mixed with distilled water and again after mixing. The measurement method is outlined in section 2.3.2.

\section{Textural analysis}

The texture analysis of dough samples was carried out with a texture analyser (TA.XT Express Enhanced, Stable Micro Systems, Godalming, UK) using the texture profile analysis method. The texture analyser was equipped with a $1 \mathrm{~kg}$ load cell and a $0.05(\mathrm{~N})$ detection range. The dough sample was made into a cuboid of $2 \mathrm{~cm}$ in length, $2 \mathrm{~cm}$ in width and $3 \mathrm{~cm}$ in thickness. The measurement parameters were as follows: probe, $\mathrm{P} / 36 \mathrm{R}$; pre-test rate, $5 \mathrm{~mm} / \mathrm{s}$; post-test rate, $5 \mathrm{~mm} / \mathrm{s}$; test rate, 
$1 \mathrm{~mm} / \mathrm{s}$; second compression waiting time, $5 \mathrm{~s}$; and compression distance, $30 \%$.

\subsection{Baking test}

\section{Biscuit preparation}

Seven kinds of biscuit samples were prepared: Control (1000 g/kg WF), W950Y050 (950 g/kg WF 50 g/kg yellow PFPF), W900Y100 (900 g/kg WF, $100 \mathrm{~g} / \mathrm{kg}$ yellow PFPF), W850Y150 (850 g/kg WF, 150 g/kg yellow PFPF), W950P050 (950 g/kg WF, $50 \mathrm{~g} / \mathrm{kg}$ purple PFPF), W900P100 (900 g/kg WF, $100 \mathrm{~g} / \mathrm{kg}$ purple PFPF), W850P150 (850 g/kg WF, 150 g/kg purple PFPF).

For each formulation, every $1000 \mathrm{~g}$ of wheat flour, or mix of the passion fruit peel flour and wheat flour, $500 \mathrm{~g}$ of floured sucrose, $200 \mathrm{~g}$ of water, $300 \mathrm{~g}$ of butter (containing $100 \mathrm{~g} / \mathrm{kg}$ of water), $10 \mathrm{~g}$ of salt and $10 \mathrm{~g}$ of baking flour were added.

The formulations were selected based on preliminary experiments. The dough was mixed for $5 \mathrm{~min}$, left at $4{ }^{\circ} \mathrm{C}$ for $30 \mathrm{~min}$, rolled to a $3 \mathrm{~mm}$ thickness, cut into circular pieces (45 mm diameter), placed on a tray and baked in a convection oven at $180^{\circ} \mathrm{C} / 20 \mathrm{~min}$. The biscuits were cooled for $20 \mathrm{~min}$ at room temperature and then packed in polyethylene bags under desiccation. In Figure 1, a schematic of the incorporation of PFPF into biscuits is depicted.

\section{Physical characteristics of biscuits}

The moisture content was tested by the AACC international method 44-15.02 (American Association of Cereal Chemists, 2000), while water activity $\left(\mathrm{a}_{\mathrm{w}}\right)$ was evaluated by a water activity meter (LabStart-aw, Novasina, Lachen, Switzerland) after equilibration at $25{ }^{\circ} \mathrm{C}$. Penetration experiments on biscuits were performed using a $2 \mathrm{~mm}$ cylindrical stainless probe to obtain the firmness value of the biscuits. The depth of penetration was $2 \mathrm{~mm}$, and the crosshead speed was $0.5 \mathrm{~mm} / \mathrm{s}$. The measurement method of colour for the biscuit samples is outlined in section 2.3.2.

\section{Sensory evaluation}

The sensory evaluation team consisted of 20 panellists. The biscuit qualities, such as colour, taste, flavour, appearance, texture, and overall acceptability, were evaluated by the panellists using a 5 -point hedonic scale ( $5=$ like extremely, $4=$ like, $3=$ neither dislike nor like, 2 = dislike and $1=$ dislike extremely). The panellists completed the evaluation independently and submitted their scores (Alongi et al., 2019).

\section{Fibre analysis of biscuits}

The dietary fibre content of the samples, such as the soluble dietary fibre (SDF), insoluble dietary fibre (IDF) and total dietary fibre (TDF), were determined by the gravimetric enzymatic method (Yapo \& Koffi, 2008).

\subsection{Statistical analysis}

All samples were tested in triplicate. The average values of all experimental results were subjected to analysis of variance (ANOVA). Significant differences at $P<0.05$ were determined using Duncan's multiple range tests with the $\mathrm{R}$ version 3.6.1.

\section{Results and discussion}

\subsection{Physical and chemical characterization of PFPF}

Table 1 summarizes the physical properties of the PFPF. The BD of the yellow and purple PFPFs were 0.43 and $0.42(\mathrm{~g} / \mathrm{mL})$, respectively. The $\mathrm{BD}$ values $(\mathrm{g} / \mathrm{mL})$ of the PFPFs were lower than

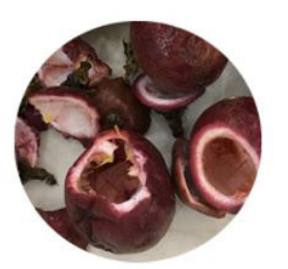

Purple passion fruit peel Yellow passion fruit peel

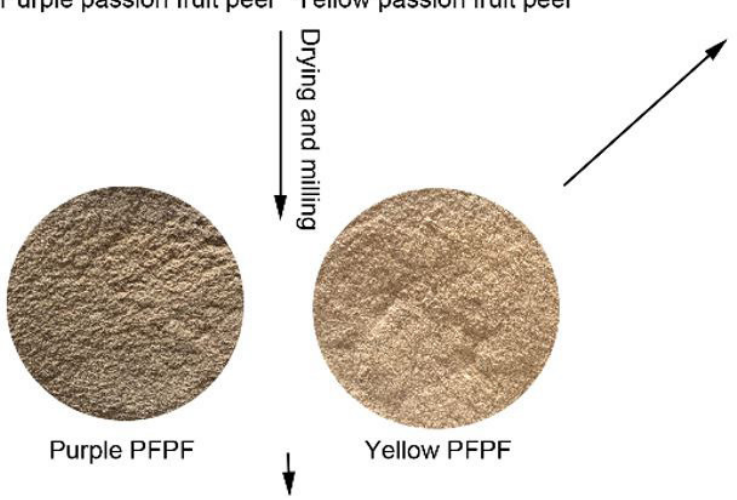

Physical and chemical characterization

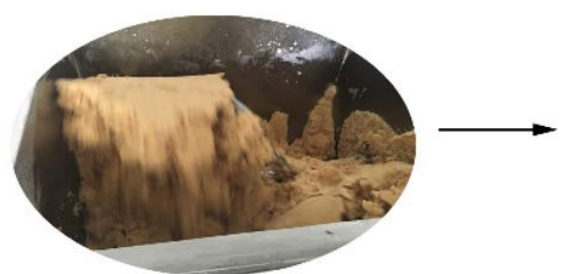

Mixing with other ingredients

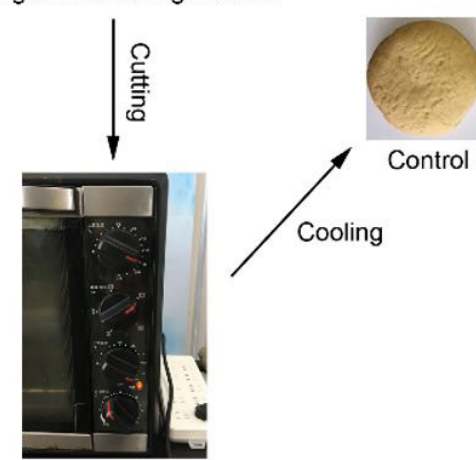

Baking
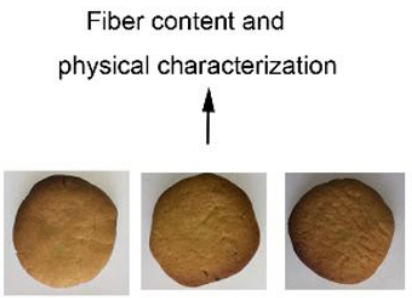

W950P050 W900P100 W850P150
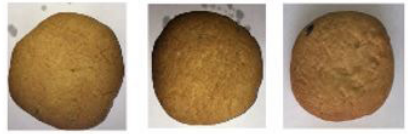

W950Y050 W900Y100 W850Y150

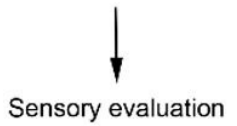

Figure 1. The schematic procedure of the incorporation of PFPF in biscuits. 
Effects of passion fruit peel flour on biscuit quality

Table 1. Physical, chemical and colour characteristics of yellow PFPF, purple PFPF and wheat flour.

\begin{tabular}{|c|c|c|c|}
\hline Physical, chemical and colour characteristics & Yellow PFPF & Purple PFPF & Wheat flour \\
\hline Bulk density $(\mathrm{BD}, \mathrm{g} / \mathrm{mL})$ & $0.43 \pm 0.01^{\mathrm{a}}$ & $0.42 \pm 0.01^{\mathrm{b}}$ & - \\
\hline Water solubility index (WSI, \%) & $35.09 \pm 0.91^{\mathrm{a}}$ & $31.73 \pm 0.85^{\mathrm{b}}$ & - \\
\hline Water holding capacity (WHC, g/g) & $8.10 \pm 0.03^{\mathrm{b}}$ & $8.30 \pm 0.07^{\mathrm{a}}$ & - \\
\hline Fat binding capacity (FAC, g/g) & $2.44 \pm 0.04^{\mathrm{a}}$ & $2.38 \pm 0.02^{\mathrm{b}}$ & - \\
\hline Swelling capacity $\left(\mathrm{SC}, \mathrm{cm}^{3} / \mathrm{g}\right)$ & $8.60 \pm 0.13^{\mathrm{b}}$ & $9.24 \pm 0.07^{\mathrm{a}}$ & - \\
\hline Total dietary fibre (TDF, \%) & $45.18 \pm 0.21^{\mathrm{b}}$ & $47.39 \pm 0.53^{\mathrm{a}}$ & - \\
\hline Soluble dietary fibre (SDF, \%) & $13.71 \pm 0.28^{\mathrm{a}}$ & $13.56 \pm 0.10^{\mathrm{a}}$ & \\
\hline Insoluble dietary fibre (IDF, \%) & $31.36 \pm 0.86^{\mathrm{b}}$ & $33.77 \pm 0.80^{\mathrm{a}}$ & - \\
\hline \multicolumn{4}{|l|}{ Colour value } \\
\hline $\mathrm{L}^{*}$ & $96.37 \pm 0.88^{\mathrm{b}}$ & $64.76 \pm 1.15^{\mathrm{c}}$ & $100.57 \pm 0.62^{\mathrm{a}}$ \\
\hline$a^{*}$ & $-8.68 \pm 0.17^{c}$ & $5.02 \pm 0.16^{\mathrm{a}}$ & $0.52 \pm 0.16^{\mathrm{c}}$ \\
\hline$b^{*}$ & $28.48 \pm 0.77^{a}$ & $13.64 \pm 0.31^{b}$ & $11.36 \pm 0.65^{c}$ \\
\hline
\end{tabular}

The significant differences $(p<0.05)$ of different samples are shown by different lowercase letters. $L^{*}$ : light; $\mathrm{a}^{*}$ : red; $\mathrm{b}^{*}$ : yellow.

those of flours obtained from mango peel and pomegranate peel, 0.60 and $0.62 \mathrm{~g} / \mathrm{mL}$ (Pathak et al., 2016; Sogi et al., 2013), respectively.

The WSI, WHC, FAC and SC values are presented in Table 1. The results obtained show that the values of WSI, WHC, FAC and $\mathrm{SC}$ of the two types of PFPF were significantly different from each other $(P<0.05)$. The yellow and purple PFPF presented a WSI of $35.09 \pm 0.91 \%$ and $31.73 \pm 0.85 \%$, respectively. This result indicates that the soluble molecular content of yellow PFPF is higher than that of purple PFPF.

From a physiological and technical point of view, WHC is an important attribute of dietary fibre. This attribute indicates the capability of the substance to hold $\mathrm{H}_{2} \mathrm{O}$ molecules under external gravity and extrusion. The mechanism of water retention of a substance mainly includes combination, hydration and physical barriers (Ku \& Mun, 2008). The WHC values of the yellow and purple PFPF are higher than those reported for mango peel flour (4.68 g/g) (Sogi et al., 2013), but comparable to that of ripe banana peel flour $(8.19 \mathrm{~g} / \mathrm{g})$ (Alkarkhi et al., 2011). The WHC value of purple PFPF $(8.30 \mathrm{~g} / \mathrm{g})$ was higher than that of yellow PFPF $(8.10 \mathrm{~g} / \mathrm{g})$, which may be related to the TDF value of purple PFPF (47.39\%) being higher than that of yellow PFPF (45.18\%). At the same time, these two kinds of PFPF also show a higher SC $\left(9.24 \mathrm{~cm}^{3} / \mathrm{g}\right.$ and $\left.8.60 \mathrm{~cm}^{3} / \mathrm{g}\right)$ than that of wheat flour, which also implies that the excessive addition of these two kinds of PFPF in the formulation of biscuits will adversely affect the moisture content during the baking process.

FAC indicates the ability of flour to retain oil that help retain the flavour components and provide improved taste to foods. This parameters has a certain relationship with the chemical composition, but the physical structure of the material is more important (Biswas et al., 2011). The FAC values of the two kinds of PFPF $(2.44 \mathrm{~g} / \mathrm{g}$ and $2.38 \mathrm{~g} / \mathrm{g})$ were higher than those reported for other peel flours, such as that of ripe banana $(1.28 \mathrm{~g} / \mathrm{g})$ (Alkarkhi et al., 2011) or citrus (2.35 g/g water-insoluble solid of fibre-rich fractions) (Chau \& Huang, 2003). This result indicates that the addition of PFPF may improve the flavour and taste of biscuits. The SDF value of purple PFPF is comparable with that of yellow PFPF, but the IDF value of purple PFPF is higher than that of yellow PFPF.
The CIELab coordinates $\left(\mathrm{L}^{*}, \mathrm{a}^{*}\right.$, and $\left.\mathrm{b}^{*}\right)$ of the PFPF and wheat flours are presented in Table 1. Clearly, the yellow and purple PFPFs were significantly $(P<0.05)$ darker $\left(L^{*}\right)$ than the wheat flour. The red $\left(\mathrm{a}^{\star}\right)$ colour of the purple PFPF was significantly $(P<0.05)$ higher than that of the yellow PFPF, and the yellow $\left(b^{*}\right)$ colour result was the opposite.

\subsection{Dough colour and textural properties analysis}

Table 2 indicates the effects of PFPF incorporation on the dough colour. The dough samples of the wheat flour with and without PFPF incorporation represented significant differences (Table 2). According to the results, the samples incorporated with the yellow and purple PFPFs showed significantly $(P<0.05)$ lower $\mathrm{L}^{*}$ values than that of the control. The $\mathrm{L}^{*}$ values decreased as the addition level of PFPF increased. This is mainly due to the original colour of the PFPF. The higher the brown-orange saturation of the colour of a sample, the higher its $a^{*}$ and $b^{*}$ values (Martínez-Cervera et al., 2011). The $\mathrm{a}^{*}$ values of the flour samples incorporating the yellow and purple PFPFs were positive, indicating the absence of a green hue. Moreover, dough incorporating the yellow PFPF represented higher $b^{*}$ values than that of the control. Additionally, dough incorporating the purple PFPF showed the opposite result.

In Table 3, the quality of dough samples was analysed by evaluating its textural properties (hardness, springiness, cohesiveness, gumminess, and resilience). Previous studies have shown that product quality can be directly and objectively evaluated through texture analysis (Carson \& Sun, 2001; Szczesniak, 2002). The results showed that the texture characteristics of the dough incorporating yellow PFPF or purple PFPF were significantly improved. According to the results, when 5\% yellow PFPF was incorporated, the hardness, springiness, cohesiveness, gumminess, and resilience of the dough samples significantly increased compared to those of the control, with values of $238.94,17.50,36.95,399.57$, and $37.73 \%$, respectively. Moreover, when $10 \%$ yellow PFPF was incorporated, the hardness and gumminess of the dough were further improved. However, the springiness, cohesiveness, and resilience of this dough were significantly decreased compared to those of the control. Further increasing the amount of addition reduced the changes in the 
Weng et al.

Table 2. Colour characteristics of doughs and biscuits made with wheat flour incorporated with PFPF.

\begin{tabular}{|c|c|c|c|c|c|c|c|}
\hline Colour value & Control & W950Y050 & W900Y100 & W850Y150 & W950P050 & W900P100 & W850P150 \\
\hline \multicolumn{8}{|l|}{ Doughs } \\
\hline $\mathrm{L}^{*}$ & $86.02 \pm 1.14^{\mathrm{A}}$ & $79.75 \pm 0.88^{\mathrm{B}}$ & $74.79 \pm 0.87^{\mathrm{C}}$ & $69.23 \pm 0.59^{\mathrm{D}}$ & $66.80 \pm 0.70^{\mathrm{E}}$ & $51.18 \pm 0.59^{\mathrm{F}}$ & $42.93 \pm 0.58^{\mathrm{G}}$ \\
\hline$a^{*}$ & $2.74 \pm 0.13^{\mathrm{D}}$ & $1.77 \pm 0.04^{\mathrm{E}}$ & $0.98 \pm 0.03^{\mathrm{F}}$ & $0.21 \pm 0.02^{\mathrm{G}}$ & $3.65 \pm 0.09^{\mathrm{C}}$ & $4.31 \pm 0.07^{\mathrm{B}}$ & $6.29 \pm 0.10^{A}$ \\
\hline$b^{*}$ & $13.27 \pm 0.10^{\mathrm{D}}$ & $17.19 \pm 0.10^{\mathrm{C}}$ & $23.78 \pm 0.49^{\mathrm{B}}$ & $26.57 \pm 0.49^{\mathrm{A}}$ & $13.56 \pm 0.34^{\mathrm{D}}$ & $11.88 \pm 0.43^{\mathrm{E}}$ & $11.15 \pm 0.64^{\mathrm{F}}$ \\
\hline \multicolumn{8}{|l|}{ Biscuits } \\
\hline $\mathrm{L}^{*}$ & $94.05 \pm 1.58 \mathrm{a}$ & $76.49 \pm 1.86 b$ & $72.33 \pm 1.72 \mathrm{c}$ & $64.70 \pm 1.17 d$ & $76.70 \pm 1.18 b$ & $72.31 \pm 0.93 c$ & $63.87 \pm 0.96 d$ \\
\hline$a^{*}$ & $5.35 \pm 0.12 \mathrm{f}$ & $11.74 \pm 0.74 \mathrm{e}$ & $27.69 \pm 1.27 \mathrm{a}$ & $22.51 \pm 1.25 b$ & $12.77 \pm 0.42 \mathrm{~d}$ & $28.44 \pm 0.72 \mathrm{a}$ & $21.12 \pm 0.92 \mathrm{c}$ \\
\hline $\mathrm{b}^{*}$ & $34.29 \pm 1.70 \mathrm{~d}$ & $44.38 \pm 1.26 \mathrm{bc}$ & $52.67 \pm 1.76 \mathrm{a}$ & $45.24 \pm 1.31 \mathrm{~b}$ & $44.64 \pm 1.18 \mathrm{bc}$ & $53.17 \pm 1.04 \mathrm{a}$ & $43.22 \pm 0.77 \mathrm{c}$ \\
\hline
\end{tabular}

Table 3. Textural properties (hardness, springiness, cohesiveness, gumminess and resilience) of different kinds of doughs.

\begin{tabular}{lrrrrrrr}
\hline \multicolumn{1}{c}{$\begin{array}{c}\text { Textural } \\
\text { properties }\end{array}$} & \multicolumn{1}{c}{ Control } & W950Y050 & W900Y100 & W850Y150 & W950P050 & W900P100 & W850P150 \\
\hline Hardness (N) & $128.253 \pm 2.342^{\mathrm{f}}$ & $434.697 \pm 3.223^{\mathrm{e}}$ & $583.081 \pm 3.742^{\mathrm{c}}$ & $724.982 \pm 3.237^{\mathrm{a}}$ & $437.639 \pm 5.149^{\mathrm{e}}$ & $550.956 \pm 4.244^{\mathrm{d}}$ & $621.968 \pm 6.218^{\mathrm{b}}$ \\
Springiness & $0.320 \pm 0.002^{\mathrm{g}}$ & $0.376 \pm 0.004^{\mathrm{c}}$ & $0.354 \pm 0.005^{\mathrm{e}}$ & $0.409 \pm 0.004^{\mathrm{b}}$ & $0.371 \pm 0.004^{\mathrm{d}}$ & $0.338 \pm 0.003^{\mathrm{f}}$ & $0.419 \pm 0.005^{\mathrm{a}}$ \\
Cohesiveness & $0.295 \pm 0.005^{\mathrm{f}}$ & $0.404 \pm 0.004^{\mathrm{c}}$ & $0.380 \pm 0.006^{\mathrm{d}}$ & $0.414 \pm 0.004^{\mathrm{b}}$ & $0.408 \pm 0.005^{\mathrm{bc}}$ & $0.367 \pm 0.008^{\mathrm{e}}$ & $0.423 \pm 0.008^{\mathrm{a}}$ \\
Gumminess & $37.092 \pm 1.235^{\mathrm{f}}$ & $185.300 \pm 2.882^{\mathrm{d}}$ & $198.956 \pm 1.705^{\mathrm{c}}$ & $313.277 \pm 4.269^{\mathrm{a}}$ & $174.898 \pm 2.828^{\mathrm{e}}$ & $186.085 \pm 2.989^{\mathrm{d}}$ & $307.415 \pm 3.422^{\mathrm{b}}$ \\
Resilience & $0.073 \pm 0.002^{\mathrm{d}}$ & $0.102 \pm 0.001^{\mathrm{a}}$ & $0.093 \pm 0.002^{\mathrm{b}}$ & $0.102 \pm 0.001^{\mathrm{a}}$ & $0.101 \pm 0.001^{\mathrm{a}}$ & $0.089 \pm 0.001^{\mathrm{c}}$ & $0.102 \pm 0.010^{\mathrm{a}}$ \\
\hline
\end{tabular}

The significant differences $(p<0.05)$ of different samples are shown by different lowercase letters. $\mathrm{N}$ : The unit of force, 1 Newton $(\mathrm{N})$ is equal to the force required to cause an acceleration of $1 \mathrm{~kg}$ of mass to 1 meter per square second.

textural properties. This change also occurs in the dough with incorporated purple PFPF. In actual industrial production, a value of hardness that is too high, such as that observed in the $10 \%$ and $15 \%$ PFPF-incorporated dough samples, is not conducive to the processing of dough.

\subsection{Analysis of biscuits}

\section{Physical characteristics of biscuits}

Figure $2 \mathrm{~A}$ indicates the moisture content of biscuits prepared with wheat flour incorporated with PFPF. With 5\% PFPF incorporation, the moisture content of the biscuit sample was reduced from $4.20 \%$ (control) to $2.20 \%$ and further increased to $3.70 \%$ with $15 \%$ PFPF incorporation. These phenomena were both observed in yellow and purple PFPF biscuit samples. There is a large amount of water-absorbent dietary fibre in the PFPF, which may lead to an increase in the moisture content of the sample. It was found in the experiment that since the amount of water added for preparing the biscuit dough was fixed, the hardness of the dough increased with increasing amounts of dietary fibre, resulting in limited moisture loss. According to a previous study, the lower the moisture of the biscuit, the longer the shelf life (Bertagnolli et al., 2014). Therefore, the addition of an appropriate amount of PFPF in biscuits will help to reduce the moisture content of the products, resulting in a longer shelf life.

Figure $2 \mathrm{~B}$ represents the for the different formulas of biscuits. According to the experimental results, when the amount of PFPF incorporated was $5 \%$, the water activity values of the biscuits were significantly reduced compared to that of the control (W950P050: 0.12 and W950Y050: 0.13). Some scholars have found that the reduction of the water activity of composite biscuits containing substances, such as fibres, is caused by their ability to absorb a large amount of water, thereby reducing the amount of available water (Ho et al., 2016). However, as the amount of PFPF increased, the water activity decreased significantly $(\mathrm{P}<0.05)$. According to previous studies, in a given product, the moisture content of the sample is positively correlated with the change in water activity, which confirms that our results are consistent with those of other scholars (Cauvain \& Young, 2009).

Figure 3C indicates the firmness of biscuits prepared with wheat flour incorporated with PFPF. Each addition level of PFPF significantly reduced the firmness of the biscuits $(\mathrm{P}<0.05)$ compared with that of the control, except for W850P150. W950Y050 and W950P050 show the lowest firmness $13.18 \mathrm{~N}$ and $15.68 \mathrm{~N}$, respectively. For yellow and purple PFPF biscuit samples, the increase in the firmness of the biscuit was accompanied by an increase in moisture content (Figure 2A) and fibre content (Figure 3). This situation was different from the results reported by other scholars (Raymundo et al., 2014; Saha et al., 2011). This may be related to the addition of fixed excipients, such as water, in this study.

Colour is an important factor affecting the food choices of consumers (Calvo et al., 2001), especially those of baked goods such as biscuits. Obviously, the surface of the biscuit samples with incorporated PFPF was significantly darker than that of the control $(P<0.05)$. Quantitative data is shown in Table 2. The result is not difficult to understand because PFPF has a significantly darker colour than wheat flour, especially that of purple PFPF. The $a^{*}$ and $b^{*}$ values of the biscuit samples with added PFPF were higher than those of the control. This behaviour was observed in other baked goods with added fruit by-products such as pineapple peel, orange peel and apple pomace (Alongi et al., 2019; Martins et al., 2017). 

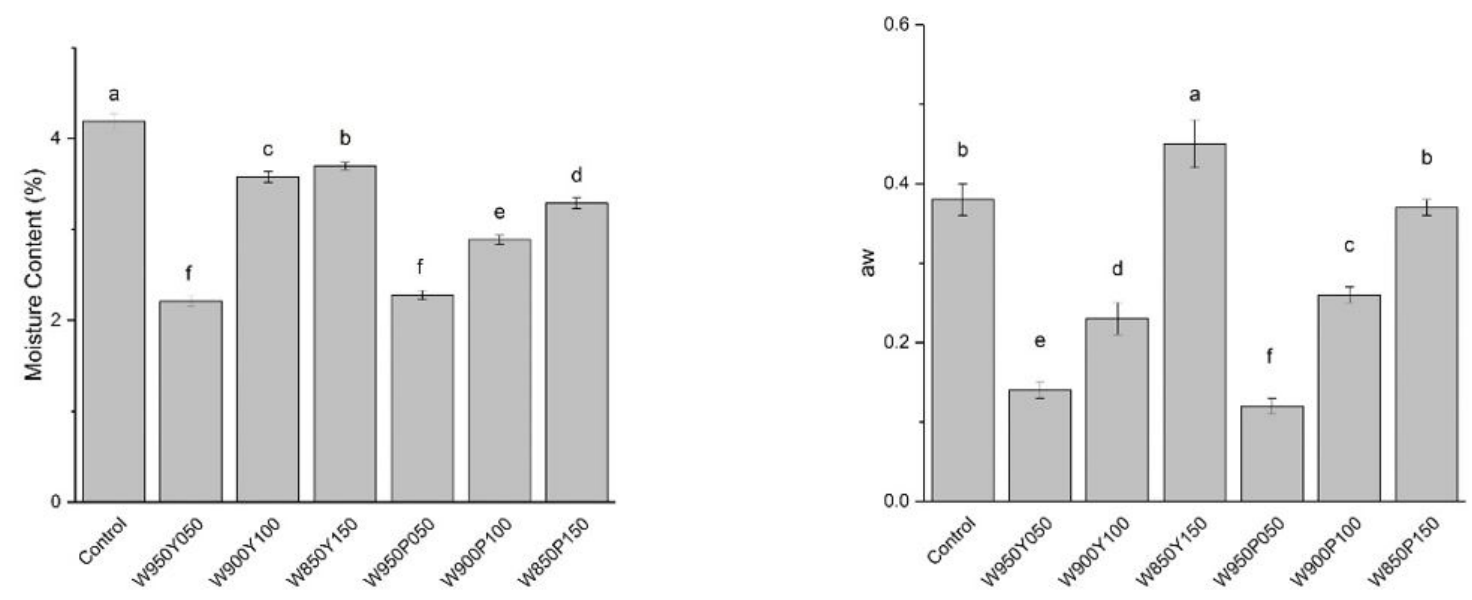

C
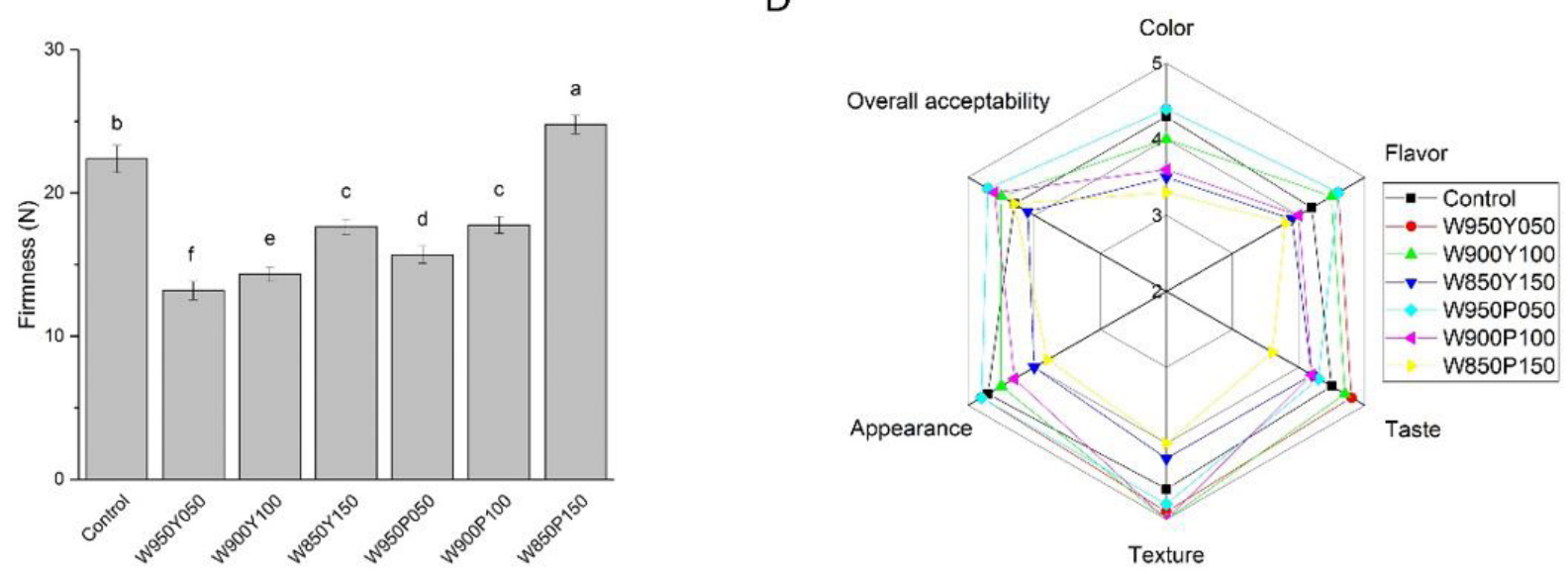

Figure 2. Characteristics of biscuits prepared with wheat flour incorporated with PFPF. Moisture content (A), water activity (a $)$ value (B), firmness $(C)$. The significant differences $(p<0.05)$ of different samples are shown by different lowercase letters. Sensorial profile (D). The spider graphic of the sensorial profile of biscuits. The centre of the graph represents point 2 of the scale, and the intensity gradually increases from the centre to the periphery.

\section{Sensory analysis}

Figure 2D shows the results of the sensory evaluation for the various biscuits. The average of the sensory indicators is marked on the corresponding axis, and the drop points are connected to form the perceived contour of the sample. Wheat flour incorporated with PFPF did affect the perception of most descriptors, such as colour and flavour. The W950Y050 and W950P050 biscuits samples (wheat flour incorporated with 5\% PFPF) show higher scores than those of the control samples. Conversely, the other biscuit samples (wheat flour incorporated with $10 \%$ and $15 \%$ PFPF) show lower scores than those of the control samples. Some scholars have used 15\% PFPF incorporation to make bread and cake. The results show that there is a negative sensory effect with 15\% PFPF incorporation compared with that of the control (Reis et al., 2018), which is comparable to the results of this study.
The sensory quality of food plays a very important role in its performance. Recently, more and more sensory evaluation methods were applied for varieties purposes in food development. For the re-innovation of foods, people used the projective methods such as word association (Judacewski et al., 2019) and shopping list (Pinto et al., 2017) to understand consumers' perception, and then formulate product innovation strategies to meet the expectations of consumers for new products. In order to improve certification process, sorting task was used as a sensory approach to differentiate cheeses form different regions (Rodrigues et al., 2020). In developing efficient marketing strategies of commercialization, the preferred attribute elicitation (PAE) methodology was applied for assessing the perceptions of consumers from different regions of Brazil about Coalho cheese samples (Soares et al., 2019). Other innovative methods, such as check-all-that-apply (CATA) questionnaire evaluated 


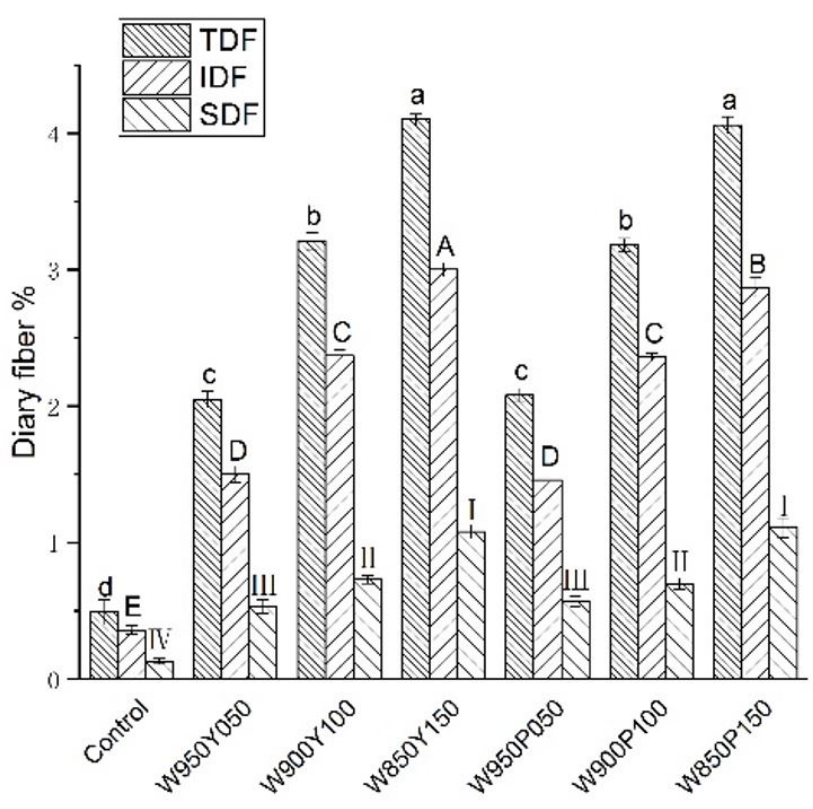

Figure 3. Effect of PFPF addition on the dietary fibre content of biscuits prepared with wheat flour fortified with passion fruit peel flour at $0 \%$, $5 \%, 10 \%$, and $15 \%$ levels. The significant differences $(p<0.05)$ of TDF, IDF and SDF are shown by different lowercase letters, uppercase letters and Roman numerals, respectively.

by multidimensional alignment analysis (Torres et al., 2017), were correlated well with conventional methods. In the stage of product technology development, traditional methods were still widely used.

\section{Dietary fibre content of biscuits}

IDF and SDF not only have differences in physical and chemical structures but also have significant differences in their functions. IDF is associated with water metabolism and intestinal peristalsis, whereas SDF is related to cholesterol control (Cummings et al., 1997). Figure 3 illustrates the changes in dietary fibre content after the incorporation of the yellow and purple PFPFs into biscuits. The experimental results show that the TDF, IDF and SDF contents of the biscuits increase with increasing PFPF incorporation. The results indicated that the TDF contents of all biscuits incorporated with PFPF were higher than that of the control. The highest value of TDF was observed with the highest amount of PFPF addition. When the amount of the blend was $15 \%$ yellow or purple PFPF, the prepared biscuit had a TDF percentage content of approximately 8 times that of the control. Similarly, the IDF and SDF contents of the biscuits with added PFPF significantly increased. However, as the amount of added PFPF increased, other qualities (such as colour, flavour and taste) of the products significantly decreased. This phenomenon is widespread in various biscuit products, such as mango peel biscuits (Ajila et al., 2008), apple pomace biscuits(Alongi et al., 2019) and orange psyllium fibre biscuits (Raymundo et al., 2014).

\section{Conclusions}

Utilization of passion fruit peel flour to prepare nutritious biscuits containing high dietary fibre is a feasible method and is beneficial for improving the nutritional value of biscuits. A suitable amount of PFPF (5\%) incorporation helps to improve the texture properties of the dough and biscuits, reduce the moisture content and water activity of the biscuits, and increase the score in sensory evaluation.

\section{Acknowledgements}

This work was supported by the National Key R\&D Program of China [Project No. 2018YFD0400203]; Fujian provincial department of science and technology, China [grant numbers 2019R1032-12, 2018R1014-1, 2018R1014-6 and 2019J01116]; and Fujian Academy of Agricultural Sciences [grant numbers DEC201821204, STIT2017-3-5 and STIT2017-3-8].

\section{References}

American Association of Cereal Chemists - AACC International (2010). Approved Methods of Analysis (11th Ed. Methods 44-15.02). AACC International: St. Paul, MN.

Ajila, C. M., Leelavathi, K., \& Prasada Rao, U. J. S. (2008). Improvement of dietary fiber content and antioxidant properties in soft dough biscuits with the incorporation of mango peel powder. Journal of Cereal Science, 48(2), 319-326. http://dx.doi.org/10.1016/j.jcs.2007.10.001.

Alkarkhi, A. F. M., Ramli, S., Yong, Y. S., \& Easa, A. M. (2011). Comparing physicochemical properties of banana pulp and peel flours prepared from green and ripe fruits. Food Chemistry, 129(2), 312-318. http:// dx.doi.org/10.1016/j.foodchem.2011.04.060. PMid:30634232.

Alongi, M., Melchior, S., \& Anese, M. (2019). Reducing the glycemic index of short dough biscuits by using apple pomace as a functional ingredient. Lebensmittel-Wissenschaft + Technologie, 100, 300-305. http://dx.doi.org/10.1016/j.lwt.2018.10.068.

Aparicio-Saguilán, A., Sáyago-Ayerdi, S. G., Vargas-Torres, A., Tovar, J., Ascencio-Otero, T. E., \& Bello-Pérez, L. A. (2007). Slowly digestible cookies prepared from resistant starch-rich lintnerized banana starch. Journal of Food Composition and Analysis, 20(3-4), 175-181. http:// dx.doi.org/10.1016/j.jfca.2006.07.005.

Ayar, A., Siçramaz, H., Öztürk, S., \& Öztürk Yilmaz, S. (2018). Probiotic properties of ice creams produced with dietary fibres from by-products of the food industry. International Journal of Dairy Technology, 71(1), 174-182. http://dx.doi.org/10.1111/1471-0307.12387.

Ben Jeddou, K., Bouaziz, F., Zouari-Ellouzi, S., Chaari, F., Ellouz-Chaabouni, S., Ellouz-Ghorbel, R., \& Nouri-Ellouz, O. (2017). Improvement of texture and sensory properties of cakes by addition of potato peel powder with high level of dietary fiber and protein. Food Chemistry, 217, 668-677. http://dx.doi.org/10.1016/j.foodchem.2016.08.081. PMid:27664685.

Bertagnolli, S. M. M., Silveira, M. L. R., Fogaça, A. D. O., Umann, L., \& Penna, N. G. (2014). Bioactive compounds and acceptance of cookies made with Guava peel flour. Food Science and Technology (Campinas), 34(2), 303-308. http://dx.doi.org/10.1590/fst.2014.0046.

Biswas, A., Kumar, V., Bhosle, S., Sahoo, J., \& Chatli, M. (2011). Dietary fibers as functional ingredients in meat products and their role in human health. International Journal of Livestock Production, 2(4), 45-54.

Calvo, C., Salvador, A., \& Fiszman, S. (2001). Influence of colour intensity on the perception of colour and sweetness in various fruit-flavoured 
yoghurts. European Food Research and Technology, 213(2), 99-103. http://dx.doi.org/10.1007/s002170100359.

Carson, L., \& Sun, X. S. (2001). Creep-recovery of bread and correlation to sensory measurements of textural attributes. Cereal Chemistry, 78(1), 101-104. http://dx.doi.org/10.1094/CCHEM.2001.78.1.101.

Cauvain, S. P., \& Young, L. S. (2009). Bakery food manufacture and quality: water control and effects. Hoboken: John Wiley \& Sons.

Chau, C.-F., \& Huang, Y.-L. (2003). Comparison of the chemical composition and physicochemical properties of different fibers prepared from the peel of Citrus sinensis L. Cv. Liucheng. Journal of Agricultural and Food Chemistry, 51(9), 2615-2618. http://dx.doi. org/10.1021/jf025919b. PMid:12696946.

Coelho, E. M., Gomes, R. G., Machado, B. A. S., Oliveira, R. S., Lima, M. S., de Azêvedo, L. C., \& Guez, M. A. U. (2017). Passion fruit peel flour - Technological properties and application in food products. Food Hydrocolloids, 62, 158-164. http://dx.doi.org/10.1016/j. foodhyd.2016.07.027.

Čukelj, N., Novotni, D., Sarajlija, H., Drakula, S., Voučko, B., \& Ćurić, D. (2017). Flaxseed and multigrain mixtures in the development of functional biscuits. Lebensmittel-Wissenschaft + Technologie, 86, 85-92. http://dx.doi.org/10.1016/j.lwt.2017.07.048.

Cummings, J. H., Roberfroid, M. B., Andersson, H., Barth, C., FerroLuzzi, A., Ghoos, Y., Gibney, M., Hermonsen, K., James, W. P. T., Korver, O., Lairon, D., Pascal, G., \& Voragen, A. G. S. (1997). A new look at dietary carbohydrate: chemistry, physiology and health. European Journal of Clinical Nutrition, 51(7), 417-423. http://dx.doi. org/10.1038/sj.ejcn.1600427. PMid:9234022.

Dhawan, K., Dhawan, S., \& Sharma, A. (2004). Passiflora: a review update. Journal of Ethnopharmacology, 94(1), 1-23. http://dx.doi. org/10.1016/j.jep.2004.02.023. PMid:15261959.

Ferreres, F., Sousa, C., Valentão, P., Andrade, P., M Seabra, R., \& GilIzquierdo, A. (2007). New C-deoxyhexosyl flavones and antioxidant properties of Passiflora edulis leaf extract. Journal of Agricultural and Food Chemistry, 55(25), 10187-10193. https://doi.org/10.1021/ jf072119y.

Freitas de Oliveira, C., Giordani, D., Lutckemier, R., Gurak, P. D., Cladera-Olivera, F., \& Ferreira Marczak, L. D. (2016). Extraction of pectin from passion fruit peel assisted by ultrasound. LebensmittelWissenschaft + Technologie, 71, 110-115. http://dx.doi.org/10.1016/j. lwt.2016.03.027.

Garcia-Armenta, E., Gutierrez, G., Anand, S., \& Cronin, K. (2017). Analysis of the failure of cracked biscuits. Journal of Food Engineering, 196, 52-64. http://dx.doi.org/10.1016/j.jfoodeng.2016.10.015.

Gurditta, H., Patel, A. A., \& Arora, S. (2019). Selection of dietary fibres for sucrose replacement in functional Chhana-murki (Indian Cottage cheese-based dessert) and their effect on sensory, physical and instrumental texture parameters. International Journal of Dairy Technology, 72(4), 633-642. http://dx.doi.org/10.1111/1471-0307.12624.

Hernández-Santos, B., Vivar-Vera, M. D. L. Á., Rodríguez-Miranda, J., Herman-Lara, E., Torruco-Uco, J. G., Acevedo-Vendrell, O., \& Martínez-Sánchez, C. E. (2015). Dietary fibre and antioxidant compounds in passion fruit (Passiflora edulis f. flavicarpa) peel and depectinised peel waste. International Journal of Food Science \& Technology, 50(1), 268-274. http://dx.doi.org/10.1111/ijfs.12647.

Ho, L.-H., Abdul Latif, N. W., \& Yildiz, F. (2016). Nutritional composition, physical properties, and sensory evaluation of cookies prepared from wheat flour and pitaya (Hylocereus undatus) peel flour blends. Cogent Food \& Agriculture, 2(1), 1136369. http://dx.doi.org/10.108 0/23311932.2015.1136369.
Judacewski, P., Los, P. R., Lima, L. S., Alberti, A., Zielinski, A. A. F., \& Nogueira, A. (2019). Perceptions of Brazilian consumers regarding white mould surface-ripened cheese using free word association. International Journal of Dairy Technology, 72(4), 585-590. http:// dx.doi.org/10.1111/1471-0307.12649.

Kaur, M., \& Singh, N. (2005). Studies on functional, thermal and pasting properties of flours from different chickpea (Cicer arietinum L.) cultivars. Food Chemistry, 91(3), 403-411. http://dx.doi.org/10.1016/j. foodchem.2004.06.015.

Kliemann, E., de Simas, K. N., Amante, E. R., Prudêncio, E. S., Teófilo, R. F., Ferreira, M. M. C., \& Amboni, R. D. M. C. (2009). Optimisation of pectin acid extraction from passion fruit peel (Passiflora edulisflavicarpa) using response surface methodology. International Journal of Food Science \& Technology, 44(3), 476-483. http://dx.doi.org/10.1111/j.1365-2621.2008.01753.x.

Krystyjan, M., Gumul, D., Ziobro, R., \& Korus, A. (2015). The fortification of biscuits with bee pollen and its effect on physicochemical and antioxidant properties in biscuits. Lebensmittel-Wissenschaft + Technologie, 63(1), 640-646. http://dx.doi.org/10.1016/j.lwt.2015.03.075.

Ku, C. S., \& Mun, S. P. (2008). Optimization of the extraction of anthocyanin from Bokbunja (Rubus coreanus Miq.) marc produced during traditional wine processing and characterization of the extracts. Bioresource Technology, 99(17), 8325-8330. http://dx.doi. org/10.1016/j.biortech.2008.03.013. PMid:18456493.

Kuniak C. Sc., L., \& Marchessault, R. H. (1972). Study of the crosslinking reaction between epichlorohydrin and starch. Starch: Biosynthesis, Nutrition, Biomedical, 24(4), 110-116. https://doi.org/10.1002/ star.19720240404.

Liew, S. Q., Chin, N. L., \& Yusof, Y. A. (2014). Extraction and characterization of pectin from passion fruit peels. Agriculture and Agricultural Science Procedia, 2, 231-236. http://dx.doi.org/10.1016/j. aaspro.2014.11.033.

MacAgnan, F. T., Santos, L. R., Roberto, B. S., de Moura, F. A., Bizzani, M., \& Silva, L. P. (2015). Biological properties of apple pomace, orange bagasse and passion fruit peel as alternative sources of dietary fibre. Bioactive Carbohydrates and Dietary Fibre, 6(1), 1-6. http://dx.doi. org/10.1016/j.bcdf.2015.04.001.

Martínez-Cervera, S., Salvador, A., Muguerza, B., Moulay, L., \& Fiszman, S. M. (2011). Cocoa fibre and its application as a fat replacer in chocolate muffins. Lebensmittel-Wissenschaft + Technologie, 44(3), 729-736. http://dx.doi.org/10.1016/j.lwt.2010.06.035.

Martins, Z. E., Pinho, O., \& Ferreira, I. M. P. L. V. O. (2017). Food industry by-products used as functional ingredients of bakery products. Trends in Food Science \& Technology, 67, 106-128. http:// dx.doi.org/10.1016/j.tifs.2017.07.003.

Morais, M., Caliari, M., Nabeshima, E., Batista, J., Campos, M., \& Soares Júnior, M. (2018). Storage stability of sweet biscuit elaborated with recovered potato starch from effluent of fries industry. Food Science and Technology (Campinas), 38(2), 216-222. http://dx.doi. org/10.1590/fst.32916.

Okpala, L. C., \& Okoli, E. C. (2013). Optimization of composite flour biscuits by mixture response surface methodology. Food Science \& Technology International, 19(4), 343-350. http://dx.doi. org/10.1177/1082013212452587. PMid:23729419.

Pathak, P., Mandavgane, S., \& Kulkarni, B. (2016). Characterizing Fruit and Vegetable Peels as Bioadsorbents. Current Science, 110(11), 2114. http://dx.doi.org/10.18520/cs/v110/i11/2114-2123.

Pinto, L., Silva, H., Kuriya, S., Maçaira, P., Oliveira, F. L., Esmerino, E., \& Freitas, M. (2017). Understanding perceptions and beliefs about different types of fermented milks through the application of projective techniques: a case study using Haire's shopping list and 
free word association. Journal of Sensory Studies, 33(3), e12326. http://dx.doi.org/10.1111/joss.12326.

Raymundo, A., Fradinho, P., \& Nunes, M. C. (2014). Effect of Psyllium fibre content on the textural and rheological characteristics of biscuit and biscuit dough. Bioactive Carbohydrates and Dietary Fibre, 3(2), 96-105. http://dx.doi.org/10.1016/j.bcdf.2014.03.001.

Reis, L. C. R. D., Facco, E. M. P., Salvador, M., Flôres, S. H., \& Rios, A. D. O. (2018). Characterization of orange passion fruit peel flour and its use as an ingredient in bakery products. Journal of Culinary Science \& Technology, 18(3), 1-17. http://dx.doi.org/10.1080/1542 8052.2018.1564103.

Robertson, J. A., de Monredon, F. D., Dysseler, P., Guillon, F., Amado, R., \& Thibault, J.-F. (2000). Hydration properties of dietary fibre and resistant starch: a European Collaborative study. LebensmittelWissenschaft + Technologie, 33(2), 72-79. http://dx.doi.org/10.1006/ fstl.1999.0595.

Rodrigues, J. F., Mangia, B. A., Silva, J. G., Lacorte, G. A., Coimbra, L. O., Esmerino, E. A., Freitas, M. Q., Pinheiro, A. C. M., \& Cruz, A. G. (2020). Sorting task as a tool to elucidate the sensory patterns of artisanal cheeses. Journal of Sensory Studies, e12562. http://dx.doi. org/10.1111/joss. 12562.

Saha, S., Gupta, A., Singh, S. R. K., Bharti, N., Singh, K. P., Mahajan, V., \& Gupta, H. S. (2011). Compositional and varietal influence of finger millet flour on rheological properties of dough and quality of biscuit. Lebensmittel-Wissenschaft + Technologie, 44(3), 616-621. http://dx.doi.org/10.1016/j.lwt.2010.08.009.

Santos, R., Silva, M., Nascimento, K., Batista, A., Moraes, J., Andrade, M., \& Barbosa, M. (2017). Prebiotic flours in dairy food processing: technological and sensory implications. International Journal of Dairy Technology, 71(51), 1-10. http://dx.doi.org/10.1111/1471-0307.12394.

Seixas, F. L., Fukuda, D. L., Turbiani, F. R. B., Garcia, P. S., Petkowicz, C. L. D. O., Jagadevan, S., \& Gimenes, M. L. (2014). Extraction of pectin from passion fruit peel (Passiflora edulis f. flavicarpa) by microwave-induced heating. Food Hydrocolloids, 38, 186-192. http:// dx.doi.org/10.1016/j.foodhyd.2013.12.001.

Silva, J. K., Cazarin, C. B. B., Bogusz, S. Jr., Augusto, F., \& Maróstica, M. R. Jr. (2014). Passion fruit (Passiflora edulis) peel increases colonic production of short-chain fatty acids in Wistar rats. Lebensmittel-Wissenschaft + Technologie, 59(2), 1252-1257. http:// dx.doi.org/10.1016/j.lwt.2014.05.030.

Singh, A., \& Kumar, P. (2018). Optimization of gluten free biscuit from foxtail, copra meal and amaranth. Food Science and Technology (Campinas), 39(1), 43-49. http://dx.doi.org/10.1590/fst.22917.

Smith, R. E., Silva Menezes, E. M., Sabaa-Srur, A. U. O., \& Wycoff, W. (2012). Potential health benefits of passion fruit peel flour. The Natural Products Journal, 2(2), 104-107. http://dx.doi.org/10.2174 /2210315511202020104.

Soares, E. K. B., Silva, R., Silva, W. P., Kuriya, S. P., Maçaira, P. M., Cyrino Oliveira, F. L., \& Esmerino, E. A. (2019). An intra-cultural investigation in Brazil using Coalho cheese and preferred attribute elicitation. Journal of Sensory Studies, 35(1), e12543. http://dx.doi. org/10.1111/joss.12543.

Sogi, D. S., Siddiq, M., Greiby, I., \& Dolan, K. D. (2013). Total phenolics, antioxidant activity, and functional properties of 'Tommy Atkins' mango peel and kernel as affected by drying methods. Food Chemistry, 141(3), 2649-2655. http://dx.doi.org/10.1016/j.foodchem.2013.05.053. PMid:23871007.

Szczesniak, A. S. (2002). Texture is a sensory property. Food Quality and Preference, 13(4), 215-225. http://dx.doi.org/10.1016/S09503293(01)00039-8.

Torres, F. R., Esmerino, E. A., Carr, B. T., Ferrão, L. L., Granato, D., Pimentel, T. C., Bolini, H. M. A., Freitas, M. Q., \& Cruz, A. G. (2017). Rapid consumer-based sensory characterization of requeijão cremoso, a spreadable processed cheese: performance of new statistical approaches to evaluate check-all-that-apply data. Journal of Dairy Science, 100(8), 6100-6110. http://dx.doi.org/10.3168/ jds.2016-12516. PMid:28571992.

Yapo, B. M., \& Koffi, K. L. (2008). Dietary fiber components in yellow passion fruit rind-a potential fiber source. Journal of Agricultural and Food Chemistry, 56(14), 5880-5883. http://dx.doi.org/10.1021/ jf073247p. PMid:18558700.

Youssef, M. K., Youssef, H. M., \& Mousa, R. M. (2014). Evaluation of antihyperlipidemic activity of citrus peels powders fortified biscuits in albino induced hyperlipidemia. Food and Public Health, 4(1), 1-9. 